\title{
Prediction of the body weight of Nguni goats
}

\author{
S.C. Slippers ${ }^{1}$, B.A. Letty $^{2}$ and J.F. de Villiers ${ }^{2}$ \\ ${ }^{1}$ School of Agricultural Sciences and Agribusiness, University of Natal, P Bag X01, Scottsville, 3209, South Africa; ${ }^{2}$ Farming \\ Systems Research Section, Kwazulu-Natal Dept of Agriculture and Environment Affairs, P Bag X9059, Pietermaritzburg, \\ 3200, South Africa. \\ Email: slipperss@nu.ac.za
}

\section{Introduction}

Kwazulu-Natal has the third largest goat population of South Africa's nine provinces (Anon., 1996), and the majority of these goats are of the indigenous Nguni-type, found in the small-scale farming sector. Knowing the body weight of a goat is important for a number of reasons, related to breeding (selection), feeding and health care (treatment doses of antibiotics, anthelmintics, and so forth). However, this fundamental knowledge is often unavailable to those working with goats in the small-scale farming sector, due to the unavailability of scales. Whilst professionals can overcome this obstacle, farmers are usually unable to do so, because even a simple weighing scale may be unaffordable. Hence, farmers have to rely on questionable estimates of the body weight of their goats, leading to inaccuracies in decision-making and husbandry. Such difficulties can be overcome by developing a simple, yet reasonably accurate method to predict the body weight. For instance, a prediction equation can be established, based on a linear body measurement (known as barymetry). The heart girth measurement has often been used as a predictor of body weight in animals, for example in cattle, horses, and sheep (Morrison, 1949; Quinn, 1980; Anon., 1988; Gatenby, 1991; Thys \& Hardouin, 1991). The relationship between heart girth and body weight in Nguni goats was studied by Myeni \& Slippers (1997), and it was found that heart girth explained 86.3 and $89.2 \%$ of the weight variation of bucks and does respectively. The objective of this study was to gain further information about the relationship between heart girth and body weight in Nguni goats in order to validate the potential of this method as a means of predicting body weight under field conditions.

\section{Materials and Methods}

Data on the age, body weight, heart girth and gender of 54 Nguni goats were collected from a flock belonging to a small-scale farmer near Impendhle, Kwazulu-Natal. Age was determined by counting the number of permanent incisors present. Body weight $(\mathrm{kg})$ was determined with an electronic scale. Heart girth $(\mathrm{cm})$ was measured with a measuring tape across the chest, directly behind the forelegs, with the goat standing squarely on all four legs. No distinction was made between pregnant and open does, since pregnancy status of the does was not known. Means, standard deviations, Pearson correlation coefficients, and the parameter estimates for the linear regression relationship ( $\mathrm{Y}=a+b \mathrm{X})$ between heart girth $(\mathrm{X})$ and body weight $(\mathrm{Y})$, were derived (Minitab Inc., 1998). Separate prediction equations were developed for bucks and does. Body weight was then predicted for individual goats in two different ways: using the prediction equations developed in this study or using the prediction equations developed by Myeni \& Slippers (1997). Hence, it was possible to make within-gender comparisons amongst actual body weight and the two sets of predicted body weights by means of the paired t-test (Minitab Inc., 1998).

\section{Results and Discussion}

The body weight results of bucks and does are summarised in Tables 1 and 2 respectively. Body weight was highly correlated $(\mathrm{P}<0.01)$ with heart girth measurement for both gender categories studied, namely $\mathrm{r}=0.939$ (bucks), and $\mathrm{r}=0.971$ (does). The respective prediction equations developed for bucks and does were: $\mathrm{Y}=-43.0277$ $+0.992924 . X\left(P<0.01 ; R^{2}=88.1 \%\right)$, and $Y=-47.6799+1.07677 X\left(P<0.01 ; R^{2}=94.3 \%\right)$. For bucks there was no significant difference between actual body weight $(23.25 \mathrm{~kg} \pm 2.73)$ and body weight predicted with the equation from the present study $(23.25 \mathrm{~kg} \pm 2.57)$, nor between actual body weight and predicted body weight based on the equation of Myeni \& Slippers (1997) (24.93 kg \pm 2.26$)$, but the two sets of predicted weights differed significantly $(\mathrm{P}<0.01)$ from one another. None of the three pair-wise comparisons of actual and predicted body weight of does differed significantly from one another (being $26.25 \mathrm{~kg} \pm 1.35,26.25 \mathrm{~kg} \pm 1.31$ and $26.52 \mathrm{~kg} \pm 1.16$ for actual body weight, current prediction and the previous study respectively). Variation in body weight was explained to a large extent by heart girth in this study, in concert with the findings of Myeni \& Slippers (1997). The results of both studies therefore confirm that the body weight of Nguni goats can be predicted with confidence from 
Short paper and poster abstracts: $38^{\text {th }}$ Congress of the South African Society of Animal Science

heart girth measurements. However, it is not known what the effect of pregnancy will be on this relationship, particularly during the last trimester of pregnancy, when there is a rapid increase in foetal weight.

Table 1: Actual and predicted body weight $(\mathrm{kg})$ of Nguni bucks in different age categories.

\begin{tabular}{|c|c|c|c|c|c|}
\hline Variable & 0-tooth & 2-tooth & 4-tooth & 6-tooth & 8-tooth \\
\hline Number & 7 & 0 & 2 & 1 & 0 \\
\hline Actual Body Weight ( \pm SEM) & $18.6( \pm 1.5)$ & - & $30.8( \pm 3.2)$ & $40.5(-)$ & - \\
\hline Predicted Body Weight $1^{*}( \pm$ SEM $)$ & $19.5( \pm 2.2)$ & - & $29.5( \pm 1.0)$ & $37.4(-)$ & - \\
\hline Predicted Body Weight $2^{* *}( \pm$ SEM $)$ & $21.6( \pm 2.0)$ & - & $30.4( \pm 0.9)$ & $37.5(-)$ & - \\
\hline
\end{tabular}

"Based on the prediction equation developed for bucks in the present study.

${ }^{* *}$ Based on the prediction equation developed for bucks ( $\left.\mathrm{Y}=-33.815+0.88 X ; \mathrm{n}=4\right)$ by Myeni \& Slippers (1997).

Table 2: Actual and predicted body weight $(\mathrm{kg})$ of Nguni does in different age categories.

\begin{tabular}{|c|c|c|c|c|c|}
\hline Variable & 0-tooth & 2-tooth & 4-tooth & 6-tooth & 8-tooth \\
\hline Number & 11 & 5 & 3 & 3 & 22 \\
\hline Actual Body Weight $( \pm$ SEM $)$ & $14.6( \pm 1.0)$ & $19.1( \pm 1.4)$ & $25.5( \pm 1.0)$ & $26.7( \pm 2.1)$ & $33.8( \pm 0.8)$ \\
\hline Predicted Body Weight $1^{*}( \pm$ SEM $)$ & $15.1( \pm 1.3)$ & $19.1( \pm 1.4)$ & $24.5( \pm 2.2)$ & $28.4( \pm 0.4)$ & $33.4( \pm 0.7)$ \\
\hline Predicted Body Weight $2^{* *}( \pm$ SEM $)$ & $16.6( \pm 1.2)$ & $20.2( \pm 1.2)$ & $24.9( \pm 2.0)$ & $28.4( \pm 0.3)$ & $32.8( \pm 0.6)$ \\
\hline
\end{tabular}

"Based on the prediction equation developed for does in the present study.

${ }^{* *}$ Based on the prediction equation developed for does $(\mathrm{Y}=-38.792+0.9512 \mathrm{X} ; \mathrm{n}=77$ ) by Myeni \& Slippers (1997).

\section{Conclusions}

Predicting the body weight of Nguni goats from a measurement of their heart girth is easy and accurate. The method needs to be refined to allow for possible differences in the body weight : heart girth relationship between heavily pregnant does (last trimester of pregnancy) and other does (i.e. either open or in the first two trimesters of pregnancy).

\section{References}

Anonymous, 1988. Using maths to check mass. Farmer's Weekly (Durban), August 19, pp. 64-66.

Anonymous, 1996. Herd numbers in South Africa. Red Meat, February, pp. 21.

Gatenby, Ruth R., 1991. Sheep. MacMillan Education Ltd., London.

Minitab Inc., 1998. Minitab Version 12.1. State College, Pennsylvania (USA).

Morrison, F.B., 1949. Feeds and feeding. $21^{\text {st }}$ Ed. The Morrison Publishing Company, Ithaca (NY).

Myeni, S.P. \& Slippers, S.C., 1997. Estimation of body weight of Nguni goats from heart-girth measurements. Proc. Ann. Symp. S. Afr. Soc. Anim. Sci. Dev. Anim. Agric. Branch. Mtunzini, RSA.

Quinn, T., 1980. Dairy farm management. Delmar Publishers Inc., Albany (NY).

Thys, E. \& Hardouin, J, 1991. Prediction of sheep body weight in markets in the far north Cameroon. Livestock Research for Rural Development 3 (1), 1-3. http://www.cipav.org.co/lrrd/lrrd3/1/hardouin.htm 